\title{
Design Problem Perception in Engineering Design Teams
}

\author{
Amirali Ommi ${ }^{1 *}$, Yong Zeng ${ }^{1 *}$, and Catharine C. Marsden ${ }^{2 *}$ \\ ${ }^{1}$ Concordia Institute for Information Systems Engineering (CIISE), \\ Faculty of Engineering \& Computer Science, Concordia University \\ ${ }^{2}$ Centre for Engineering in Society, Concordia University \\ *Corresponding Authors: a_ommi@encs.concordia.ca, zeng@ciise.concordia.ca, c.marsden@ concordia.ca
}

\begin{abstract}
Engineering design is a decision making process that needs a good perception of the design problem to be solved. Design problems are usually solved in a team. Teams need the existence of a good design problem perception to create design solutions. This study provides an approach for elaborating a descriptive model to describe how the perception process works within a design team. This study is going to propose an approach for integrating a theoretical model of design creativity with team mental models, so they can be used for elaborating the descriptive model of perception in design teams. The NSERC Chair in Aerospace Design Engineering (NCADE) at Concordia University holds a capstone project which will be considered to be used as a test bed for validating proposed model through experimental analysis. Proposed experiments and further research are introduced at the end of paper.
\end{abstract}

Keywords: Perception, Design Problem, Engineering Design Team, Team Mental Model, Capstone Project.

\section{INTRODUCTION}

Engineering design is a complex problem solving process with the necessity of coping with different types of critical situations [1]. Another definition for engineering design provided by Accreditation Board for Engineering and Technology Inc. is as follow. Engineering design is a decision-making process which deals with the optimal converting of resources in order to meet stated needs [2]. Thus, engineering design is a decision making process dealing with optimal conversion of resources into a final product or service in order to solve a problem and satisfy requirements. This can be mentioned as a decision making process which is dealing with problem solving where the problem is a design problem. According to the engineering design definitions mentioned above, a design team must be able to collaborate effectively on the decision making process that deals with the design problem. The team which is involved in a decision making process need a good understanding of the problem to perform well on that. This makes the perception of the problem important.

Team perception of the design problem plays an important role for making the design team capable of dealing with the decision making process during the design problem. A formal model of design, including the engineering system, design requirements, and the design process, covers the core of an engineering design problem [3]. The design process and the problem are both complex usually.

Perception is the process where a person selects, organizes, identifies and interprets the sensory information in order to understand the environment. It is the most fundamental process that happens to each design activity. Perception takes place in the brain as a sequence of complex operations, to interpret our sensory information. Understanding how perception works will help engineering designers to better understand their targeted customers because customers judge and choose products through their perception, prior knowledge and expectations.

Based on the previous work by Tan et al. [4], designers with good perception of the design problems are equipped with relevant skills, knowledge and effect in the context of the design problem. These designers will be able to provide a clear definition of the problems, come up with a better question list to be used for eliciting requirements, create a better requirement list, and generate better conceptual design solutions. From Tan et al. [4]'s experiments, it is tentative to think that equipping designers with relevant knowledge, skills, and affect in a generic context of design problems can help designers to transfer this knowledge, skills and affect to new design problems without prior related design experience. Perception is inevitably involved in the design decision process which is important for providing solutions to the design problem.

Design teams are made up of individual designers, each bringing their own knowledge, experience, and intuition to navigate the design space and recursively refine both problem and solutions until a satisfying outcome is reached [5]. Teams with right characteristics perform more effectively than the mere sum of the constituent team members. However, teams with the wrong characteristics 
may function much less effectively than the sum of individuals in certain situations [6]. One common thing to different definitions of design teams is that they all mention more than one person is involved in the process and they have interactions together. As an example, size of a team and members' skills in collaboration can be mentioned as basic characteristics. A team which is capable of making effective interaction can perform well toward achieving a good solution to the design problem.

As discussed earlier, good perception of design problem is needed to provide better solutions. The result from a perception process is usually described by the concept of mental model. Mental model is defined as a mechanism whereby humans generate a description of system purpose and form, explanations of system functioning and observed system states, and predictions of future system states. An individual's mental model (e.g., mental model of a design problem) can reflect individual's perception of reality [7]. Design problems are usually solved in a design team where more than one designer is involved. This research is interested in developing a framework to describe how the perception process works in a context of engineering design problem being solved by a design team. This framework can be applied to improve design problem perception and in turn the design team performance.

\section{AN APPROACH TO PERCEPTION OF CONCEPTUAL DESIGN PROBLEM IN DESIGN TEAMS}

\subsection{Perception Process in a Team}

In the previous works conducted in the Concordia CIISE Design Lab, a theoretical model of design creativity [8] was proposed to describe perception of a real workload. The perception process of a design problem for an individual is described by Tan et al [4]. A designer uses knowledge $\left(\mathrm{K}^{\mathrm{P}}\right)$, skill $\left(\mathrm{S}^{\mathrm{P}}\right)$ and affect $\left(\mathrm{A}^{\mathrm{P}}\right)$ to perceive workload from a design problem. During the perception process, knowledge, skills and affect being used $\left(\mathrm{K}^{\mathrm{P}}, \mathrm{S}^{\mathrm{P}}\right.$, and $\mathrm{A}^{\mathrm{P}}$ ) will work together on the real workload $\left(\mathrm{W}^{\mathrm{L}}\right)$ and will result in a perceived workload $\left(\mathrm{W}^{\mathrm{P}}\right)$. The real design problem which exists and needs to be solved can be accounted as real workload. The result of the perception process which happens to an individual is accounted as the perceived workload; it can be different among different individuals and is not necessarily the same as the real design problem. This perception process is illustrated in Fig. 1 [4].

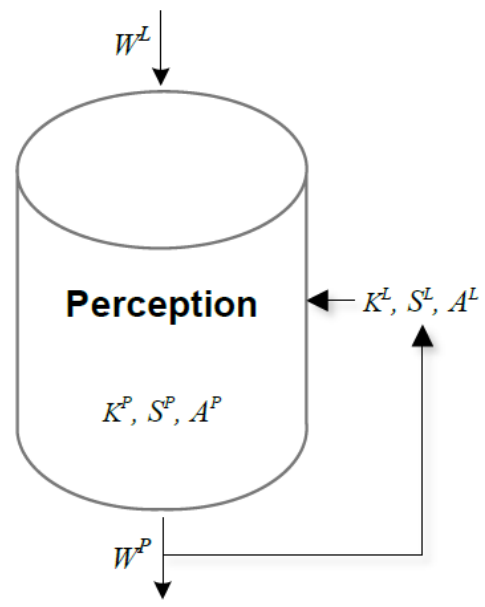

Fig. 1. Perception process for a design problem workload [4].

An individual's mental model reflects the individual's perception of reality. Accordingly, mental models vary in their accuracy and coherence. When the members of a team organize their knowledge of team tasks, equipment, roles, goals, and abilities in a similar fashion, they share a mental model [7]. Shared mental models are important for coping with tasks with difficult communication. Two people hold a shared mental model if they generate similar descriptions, explanations and prediction of the system [9]. Team performance can benefit from shared mental models in situations with a high need of information exchange in the team. Shared mental models are important for tasks that require highly coordinated actions between different team members. This coordination results in better planning, thereby improving coordinated team decision making and performance [10].

Team mental models are built based on the common structure among individuals' mental models. Team mental models describe both individual mental models and how they are shared or distributed within a team. The term team mental model is not meant to only refer to multiple levels or sets of shared knowledge or just to an aggregate of the individual mental models, but also to a synergistic functional aggregation of the teams mental functioning representing similarity, overlap, and complementarity [10]. Team mental models can reflect the perception of reality for a team in the same fashion as individual mental model does for individuals. This study proposes describing team perception of reality using team mental models.

Individuals perceive workload based on their own knowledge, skills and affect. Within a team individuals share their perception of design problem across the team 
using their collaboration and communication skills in order to make a unique perception within a team, so the team can perform more effectively on one design problem. As the perception process happens in designer's brain, it can happen in team's brains which is the team mental model.

The approach introduced here proposes using the model for describing perception process of a conceptual design problem for an individual in combination with team mental models which are accounted as a reflection of team perception. Using this combination it would be possible to integrate the parameters which are accounted in individual perception model (i.e., knowledge, skills and affect) as well as team characteristics (e.g., size, interaction, etc.) to describe how the perception process works in a team, how it can be diversified across a team, and how it can change.

\subsection{Proposed Method for Developing Team Perception Descriptive Model}

Many students with different backgrounds are involved in the NCADE capstone project. The objective of these students is to provide a conceptual design of an aircraft with specific requirements. None of the subjects has any experience with the aircraft design. At the beginning of the aircraft design project, when they start to work on the design problem, students have different skills, knowledge and affect. Students have different skills, knowledge and affect because they are from different majors, have different backgrounds, and hold different personalities.

When there is no shared perception at the start of a design project, actors need to discuss the issues on hand, and they have to learn from each other. This discussion and learning will lead to increasing sharedness of design problem perception across design team. Shared perception is similar to the (individual) perceptions of actors depicting how the design content is conceptualized [11].

As the participants work together for a significant amount of time which is an academic year in the NCADE capstone project; they use different skills and gain new knowledge, also they share their achievements together by means of collaboration and communication which make them to gain a shared perception of the design problem, builds the team mental model and leads to a more common perception of the design problem across team. However, the accuracy and coherence of the perception is subject to discussion and more experiments.

There exists different methods and materials in mental models literature which can be used for assessing designers' perception of the design problem based on their mental models. Surveys, progress reports, presentations, and other artefacts of the design process for the capstone projects can be used for this purpose, however the methods and tools are not limited to the mentioned artefacts.

By collecting mental models of the NCADE capstone students who are working on a conceptual design problem, we would be able to assess their perception of the design problem and by monitoring this reflection of their perception over time we would be able to describe the perception process in a team according to team characteristics and its change over time. For this purpose, the proposed approach in the previous section will be utilized.

\section{DISCUSSION AND FUTURE WORK}

An approach for elaborating a descriptive model for design problem perception across a design team is proposed in this study. For elaborating this descriptive model, a validated model for individual perception process of a design problem is proposed to be used in combination with team mental models. The perception process model is based on a theoretical model of design creativity. Team mental models are well-known tools for studying group behaviors in the literature of design. This integration makes it possible to scale up the perception model to a team level.

As a correct perception of a design problem is crucial to solving it, by being capable of describing the perception process, we might be able to improve the perception process. The improvement of the perception process might be facilitated by educating designers with appropriate knowledge and skills through different methods of teaching. This improvement will result in a better problem solving and lead to a better design solution by the team.

For future work, experimental analysis is intended for framing, formulating and validating the descriptive model. The diversity in perception of one design problem across an engineering design team can be studied as well and to be described by the proposed model. As discussed in the paper perception across a team is expected to converge as the team collaborate on the design problem. Validating this hypothesis using experimental analysis based on the proposed model is expected to be done in the future.

\section{Acknowledgements}

The research presented in this paper is financially supported by the NSERC chair in Aerospace Design Engineering (NCADE) program. 


\section{References}

[1] P. Badke-Schaub and A. Gehrlicher, "Patterns of decisions in design: Leaps, loops, cycles, sequences and meta-processes," Proc. 14th Int. Conf. Eng. Des., pp. 110, 2003.

[2] Accreditation Board for Engineering and Technology Inc, "Criteria for accrediting engineering programs," Cycle. p. 25, 1999.

[3] Y. Zeng, "Axiomatic theory of design modeling," $J$. Integr. Des. Process Sci., vol. 6, no. 3, pp. 1-28, 2002.

[4] S. Tan, T. A. Nguyen, and Y. Zeng, "Roles of perception in engineering design," Proceeding TMCE 2016, pp. 1-9, 2016.

[5] M. W. Tracey, "Design Team Collaboration with a Complex Design Problem," no. July, pp. 215-229, 2015.

[6] C. McComb, J. Cagan, and K. Kotovsky, "Linking Properties of Design Problems to Optimal Team Characteristics," Submitt. to ASME IDETC 2016, no.
August, pp. 1-13, 2016.

[7] B. Lim and K. J. Klein, "Team mental models and team performance: a field study of the effects of team mental model similarity and accuracy," J. Organ. Behav., vol. 27, no. 4, pp. 403-418, Jun. 2006.

[8] T. A. Nguyen and Y. Zeng, "A theoretical model of design creativity: Nonlinear design dynamics and mental stress-creativity relation," J. Integr. Des. Process Sci., vol. 16, no. 3, pp. 65-88, 2012.

[9] M. S. Avnet and A. L. Weigel, "The Structural Approach to Shared Knowledge: An Application to Engineering Design Teams," Hum. Factors, vol. 55, no. 3, pp. 581594, 2012.

[10] P. Badke-Schaub, A. Neumann, K. Lauche, and S. Mohammed, "Mental models in design teams: a valid approach to performance in design collaboration?," CoDesign, vol. 3, no. 1, pp. 5-20, 2007.

[11] M. Kleinsmann, J. Buijs, and R. Valkenburg, "Managing shared understanding in collaborative design projects," in INTERNATIONAL CONFERENCE ON ENGINEERING DESIGN, 2005, pp. 1-14. 